\title{
Commentary on 'How Many Deaths Can Be Prevented by Newborn Screening for Congenital Adrenal Hyperplasia?' by Grosse and Van Vliet, Hormone Research, 2007;67:284-291
}

\author{
Kelly R. Leight \\ CARES Foundation, Union, N.J., USA
}

I strongly encourage further consideration of the conclusions made by Grosse and Van Vliet [1], published in the last issue of Hormone Research. While these researchers should be commended for examining the effectiveness of congenital adrenal hyperplasia (CAH) infant testing, their conclusion that infant death due to adrenal crisis in salt-wasting $\mathrm{CAH}$ in firstworld countries would be $4 \%$ or less without screening for $\mathrm{CAH}$ is highly questionable as well as dangerously narrow in its scope.

CARES Foundation, Inc. is a non-profit organization that provides support to individuals and families affected by $\mathrm{CAH}$, and I serve as its Executive Director. I am also the parent of a child with a form of CAH. I have seen the devastation that can occur when we fail to screen and families suffer unnecessary loss due to a lack of proper diagnosis.

Grosse and Van Vliet's conclusions fail to consider autopsy rates and misdiagnoses as well as ignore the plight of children living in economies that are neither 'contemporary' nor 'advanced'. Any analysis must take into account the following:
- It is difficult to calculate how many deaths could have been prevented by newborn screening for $\mathrm{CAH}$ unless there is a $100 \%$ autopsy rate for infant deaths. Due to the sudden onset of adrenal crisis, generally within the first 2 weeks of life, and various obstacles to obtaining a rapid diagnosis, undetected CAH-affected children who die are often classified as having died for some reason unrelated to $\mathrm{CAH}$. Without performing an autopsy on every child that dies, we cannot know the true rate of death attributable to CAH.

- The symptoms of adrenal crisis easily can be mistaken as signs of complications of prematurity, gastrological or renal difficulties, failure to thrive and any number of other conditions. Babies are misdiagnosed, therefore inappropriately treated, and may die without $\mathrm{CAH}$ ever having been identified as the true cause of death.

- National Newborn Screening and Genetics Resource Center records for 2006 estimate 3.3 million babies had access to mandated $\mathrm{CAH}$ newborn screening last year. Genetic studies have shown that classical CAH occurs in 1 in 15,000 births; at least 220 children should have been diagnosed with CAH. Only 97 were detected through newborn screening and another 9 in clinic. Over $56 \%$ of presumed cases of $\mathrm{CAH}$ went undetected.

- Finally, the World Bank estimates that of the 6 billion people living in the world today, 1 billion receive $80 \%$ of global income, and more than 1 billion barely survive on less than a dollar a day. The plight of a huge sector of the world's population is ignored by this study.

Certainly great strides have been made in the diagnosis and treatment of $\mathrm{CAH}$ around the world. However, it is clear we still have a long way to go and only though more comprehensive research will we really come to know the rate of mortality due to $\mathrm{CAH}$.

\section{Reference}

1 Grosse SD, Van Vliet G: How many deaths can be prevented by newborn screening for congenital adrenal hyperplasia? Horm Res 2007;67:284-291.

\section{KARGER \\ Fax +4161306 1234 E-Mail karger@karger.ch} www.karger.com
Kelly R. Leight

CARES Foundation

2414 Morris Avenue, Suite 110

Union, NJ 07083 (USA)

Tel. +1 973912 3895, Fax +1973912 8990, www.caresfoundation.org 